Case Report

\title{
TWO PHASE FOR A BETTER FACE!! TWIN BLOCK AND HEADGEAR FOLLOWED BY FIXED THERAPY FOR CLASS II CORRECTION
}

\author{
U S Krishna Nayak ${ }^{1}$, Ashutosh Shetty ${ }^{2}$, Crystal Runa Soans ${ }^{3}$ \& Vivek Bhaskar ${ }^{4}$ \\ A.B. Shetty Memorial Institute of Dental Sciences, Nitte University, Mangalore, Karnataka, India \\ ${ }^{1}$ Dean (Academics) \& Head ${ }^{2}$ Professor, ${ }^{3}$ Lecturer, ${ }^{4}$ Post Graduate Student, Department of Orthodontics \& Dentofacial \\ Orthopaedics, A.B. Shetty Memorial Institute of Dental Sciences, Nitte University, \\ Mangalore - 575018, Karnataka, India.

\section{Correspondence: \\ Vivek Bhaskar} \\ Post Graduate, Department of Orthodontics \& Dentofacial Orthopaedics \\ A.B. Shetty Memorial Institute of Dental Sciences, Nitte University, Mangalore - 575 018, Karnataka, India. \\ E-mail : vivek.libra@gmail.com.
}

\begin{abstract}
:
Correction of a skeletal sagittal Class II in a growing child can be done either in one single phase of treatment, or in two phases, i.e a first phase of functional appliance to reduce the severity of the skeletal discrepancy, followed by fixed appliance therapy to refine the occlusion. This 2 phase treatment has quite a few advantages such as early correction of the facial profile is seen by the child and parent, which motivates them, as well as, reduces the social handicap produced as a result of the malocclusion. Hence, this case report describes the treatment of a Class II child, with a Twin block appliance followed by fixed orthodontic treatment.
\end{abstract}

Keywords : Two phase treatment, Twin block, Headgear.

\section{Introduction :}

Class II malocclusions can be due to prognathic maxilla, or retrognathic mandible, or both. In a growing patient, functional appliances are most widely chosen to correct the skeletal discrepancy making use of the natural growth potential. Usually, it is a 2 phase treatment, where in the skeletal discrepancy is corrected first, followed by detailing of the occlusion using fixed mechanotherapy.

A variety of functional appliances are at our foray to correct class II malocclusions like activator, functional regulator, twin block etc. The twin block, given by Clark ${ }^{(1)}$, is a very commonly used appliance for many reasons; it has reduced bulk unlike other appliances, patient adjusts to speech and other functions very quickly, it can be fixed to the teeth in

\begin{tabular}{|c|}
\hline Access this article online \\
\hline Quick Response Code \\
\hline
\end{tabular}

non-compliant cases, patient immediately sees the changes upon wearing the appliance which acts a s a o s i t i v e reinforcement. Compared to other appliances, twin block seems to be more useful in causing sagittal and vertical changes. ${ }^{(2)}$

This case report is of an 11 year old boy, who presented with a skeletal Class II, who was successfully treated in 2 phases- first phase of functional therapy using Twin Block, followed by a second phase of fixed mechanotherapy.

\section{Case Report :}

An 11 year old boy, Nidhin, reported to the Department of Orthodontics, A.B.Shetty Memorial Institute of Dental Sciences with a chief complaint of forwardly placed upper front teeth.

He had no significant medical or dental history.

On extra oral examination (FIGS 1-4), he presented to be Mesomorphic, Brachycephalic and Euryproscopic, with a convex profile, consciously competent lips, Class II apical bases, and recessive chin. 


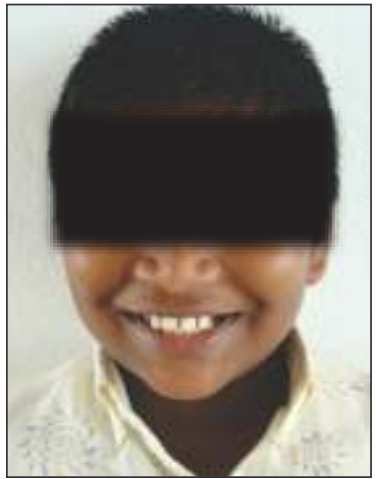

FIG 1

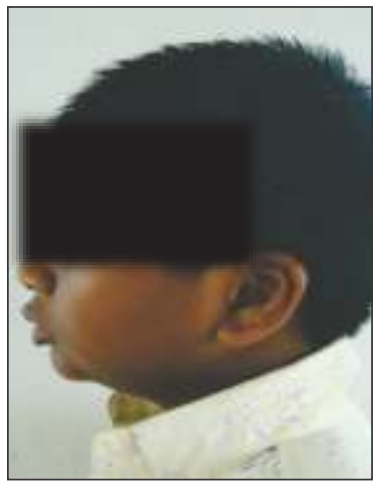

FIG 3

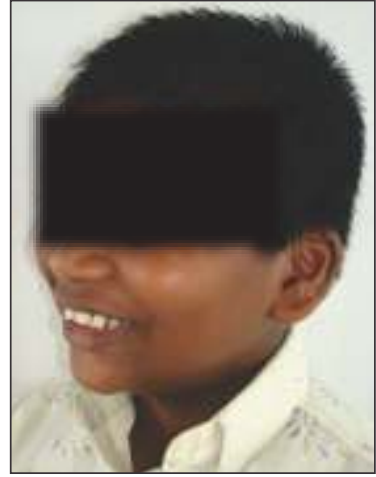

FIG 2

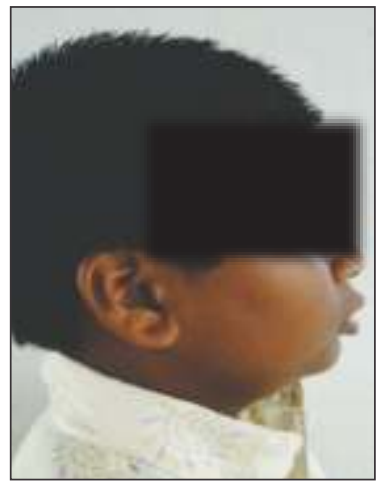

FIG 4
On intraoral examination (FIGS 5-10), dentition was in the mixed dentition stage. Generalised spacing was seen in the anterior segment of the maxillary arch.On occlusion, Molar relation was Class II bilaterally, with overjet of $12 \mathrm{~mm}$ and overbite of $4 \mathrm{~mm}$, and the lower dental midline was shifted to the right side by $3 \mathrm{~mm}$.

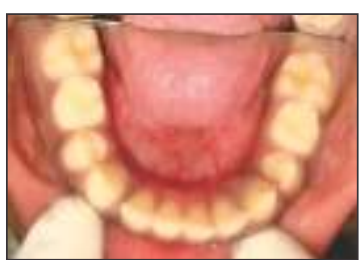

FIG 5

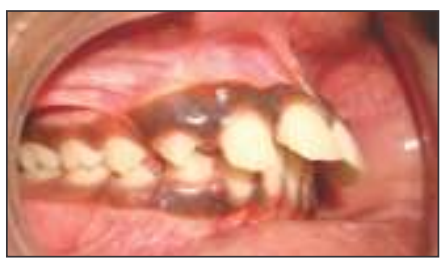

FIG 7

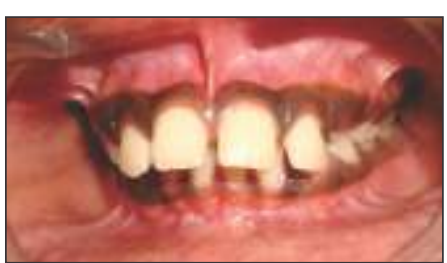

FIG 6

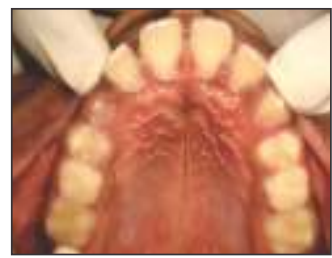

FIG 8

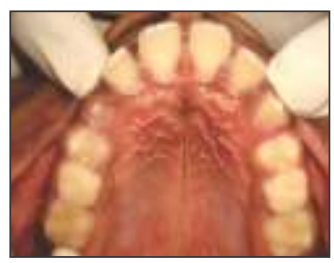

FIG 9
The cephalometric analysis of the patient (Image 10) revealed him to be a Skeletal Class II with a prognathic maxilla, retrognathic mandible, recessive chin, horizontal growth, proclined anterior teeth and an acute nasolabial angle.

An analysis of the hand wrist radiograph (FIG 11) revealed the patient to be in the SMI 3 stage of skeletal maturation indicating $65-85 \%$ growth was still remaining.

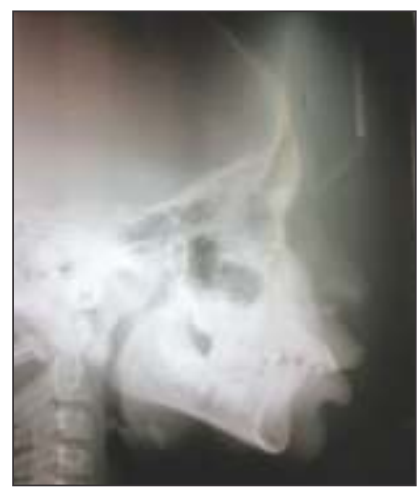

FIG 10

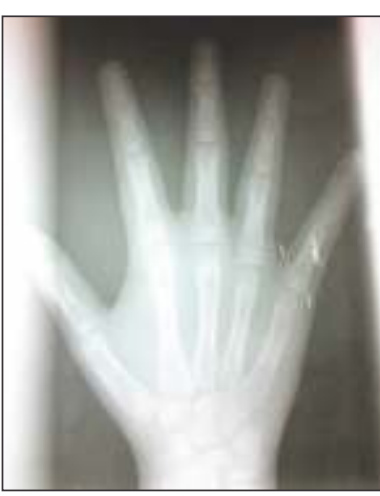

FIG 11
PRE TREATMENT OPG (FIG 12)

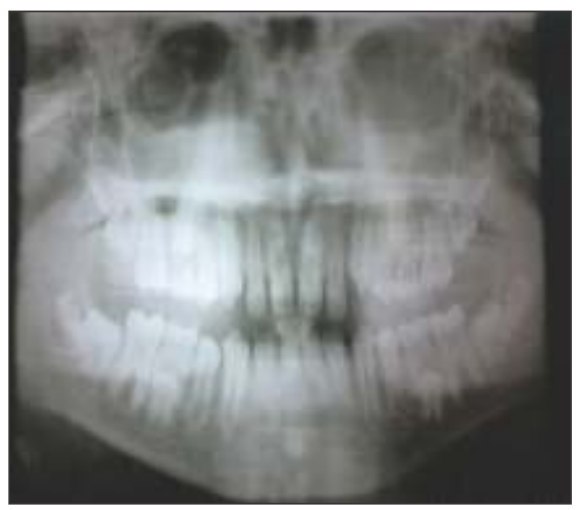

PRE TREATMENT CEPHALOGRAM VALUES (Table 1)

\begin{tabular}{|l|c|}
\hline Measurement & Values \\
\hline SNA & 87 \\
\hline SNB & 78 \\
\hline ANB & 9 \\
\hline WITT'S APPRAISAL & $5 \mathrm{~mm}$ \\
\hline FMA & 20 \\
\hline Sn-Go-Gn & 30 \\
\hline Upper Incisor- NA & $40 / 9$ \\
\hline Lower incisor - NB & $32 / 6$ \\
\hline Lower incisor- Mandibular plane & 103 \\
\hline Interincisal angle & 100 \\
\hline Nasolabial Angle & 80 \\
\hline
\end{tabular}

\section{Diagnosis:}

Using the above, the diagnosis was arrived to be:

1. Skeletal- Class II apical bases.

2. Dental- Class II div 1 malocclusion.

3. Soft tissue- Everted lips with acute nasolabial angle. 
Visual Treatment Objective (VTO): (FIGS 13, 14)

The VTO was positive, indicative that mandibular advancement would benefit the patient.

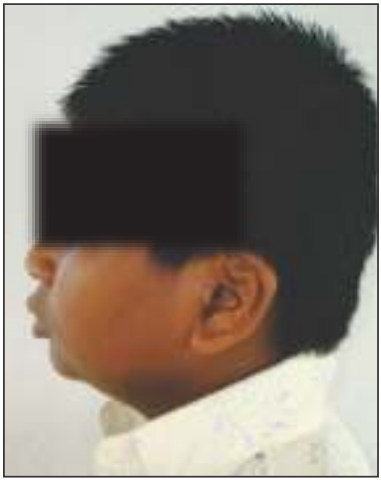

FIG 13

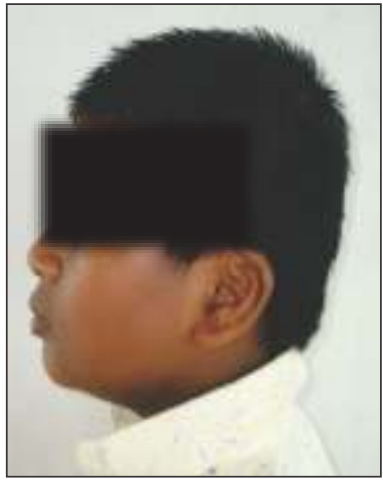

FIG 14

TREATMENT OBJECTIVES:

Based on the above pre- treatment findings, the treatment objectives were to:

1. Correction of Class II Skeletal relationship

2. Correction of overjet and overbite

3. Obtain Class I molar and canine relationship.

4. Achieve optimal facial balance and esthetics. TREATMENT PLAN:

1. Phase 1- Growth modification- Using Twin Block and Headgear.

2. Phase 2- Fixed mechanotherapy using Pre Adjusted Edgewise brackets (MBT 0.022 slot).

\section{TREATMENT PROGESS:}

1. Twin Block plus headgear:

Twin block was fabricated with a bite opening of $5 \mathrm{~mm}$ in the pre molar region with sagittal advancement of $7 \mathrm{~mm}$. (FIGS 15-19)

The appliance was delivered and the patient was asked to wear the appliance full time.

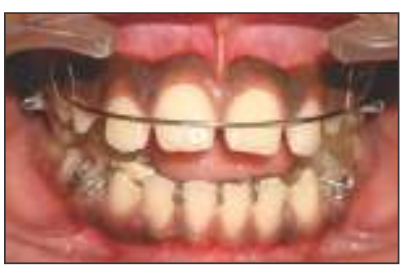

FIG 15

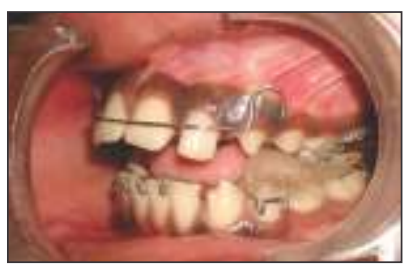

FIG 17

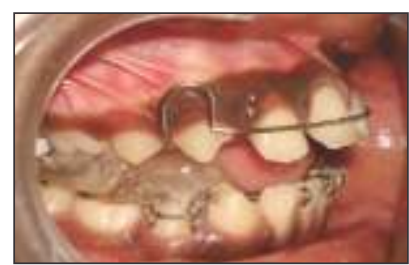

FIG 16

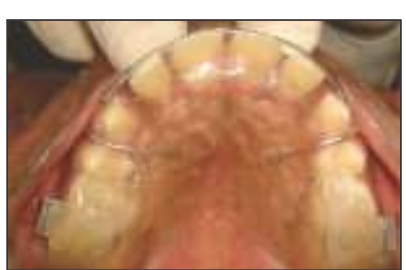

FIG 18

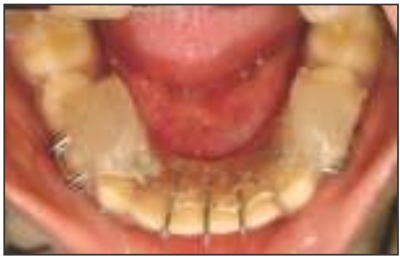

FIG 20

Alongside, from the second month onwards, a high pull headgear was given (FIGS 20,21) with a force of $400 \mathrm{~g}$ bilaterally. The headgear was used to restrain the prognathic maxilla. ${ }^{(4)}$

\section{Headgear:}

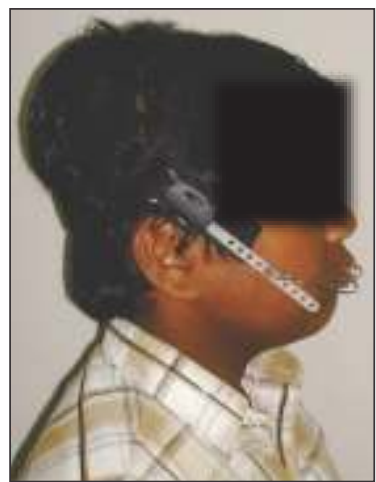

FIG 20

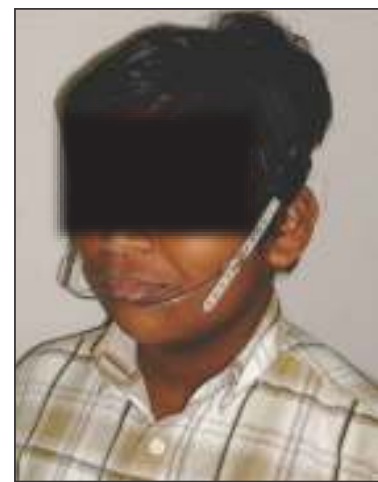

FIG 21

The appliance was worn full time for a period of 12 months. Post Twin Block-Headgear Intra Oral Images: (FIGS 22-26)

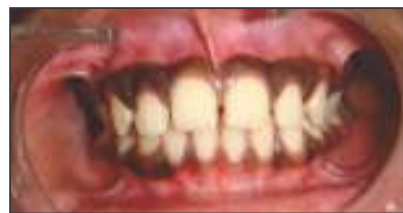

FIG 22

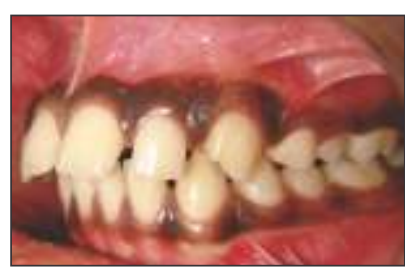

FIG 24

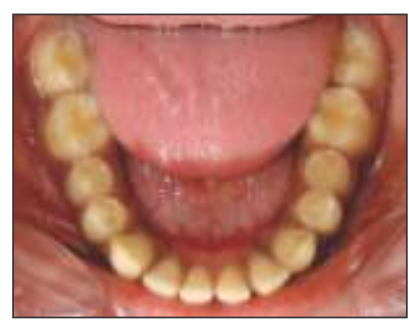

FIG 26

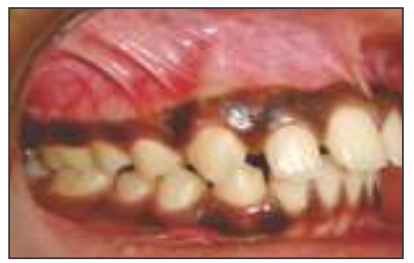

FIG 23

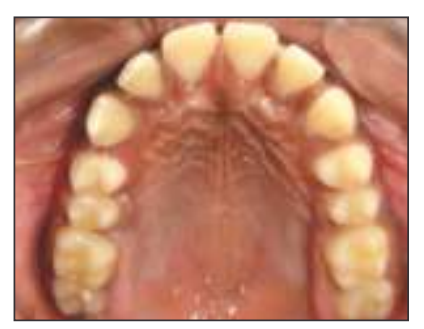

FIG 25 
Post Twin Block-Headgear Extra Oral Images (Figs 27-31)

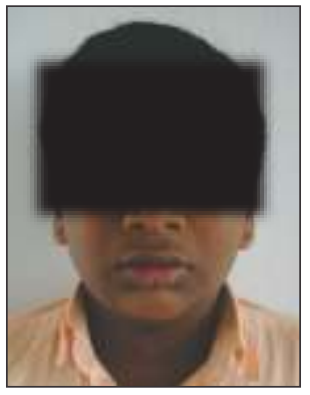

FIG 27

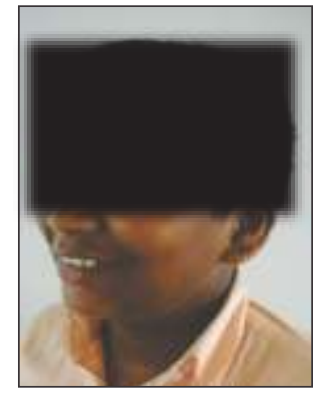

FIG 28

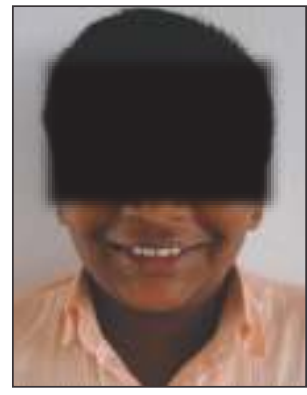

FIG 29

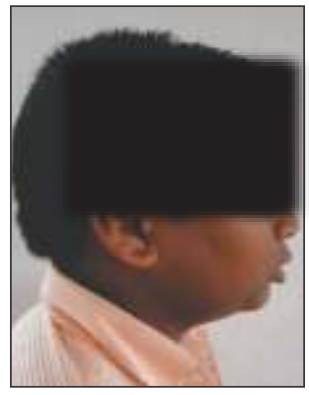

FIG 30

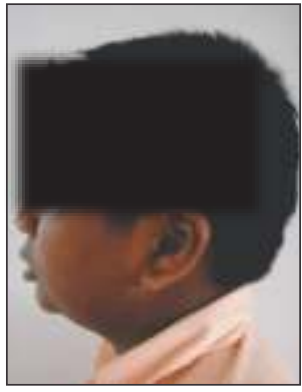

FIG 31

PHASE 2- FIXED ORTHODONTIC TREATMENT

Following 12 months of functional and orthopaedic therapy, fixed orthodontic treatment was started with Pre Adjusted Edgewise (MBT 0.022" prescription).

Levelling and alignment was done from initial $0.016 \mathrm{NiTi}$ wires till the final arch wire of $19 \times 25 \mathrm{~S} . \mathrm{S}$ was in place.

Mid Treatment Intra Oral Photographs (Figs 32-36)

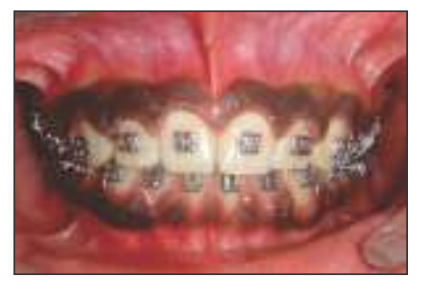

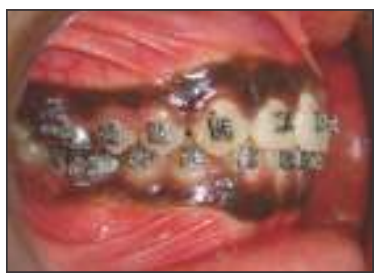

FIG 33

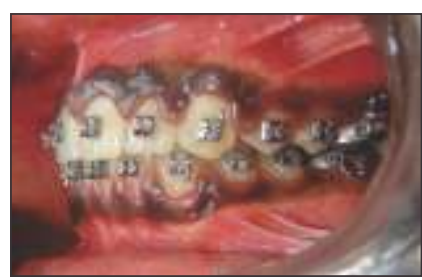

FIG 34

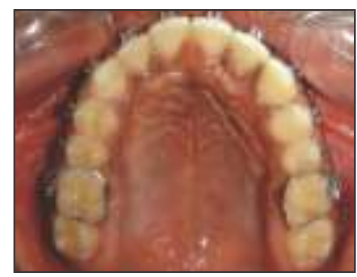

FIG 35

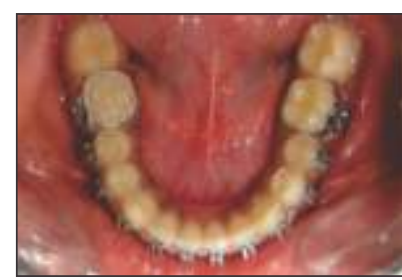

FIG 36

The fixed orthodontic treatment was completed in a period of 20 months, with the total treatment time being 32 months.

Post Treatment Photographs (Figs 37-46)

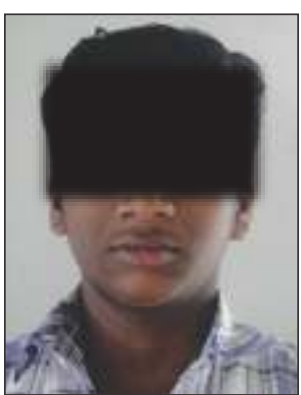

FIG 37

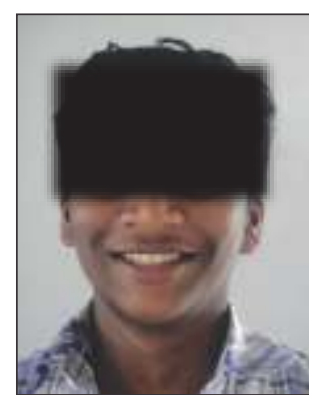

FIG 38

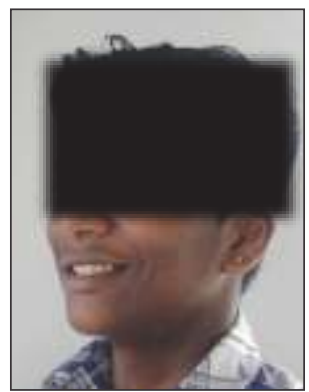

FIG 39

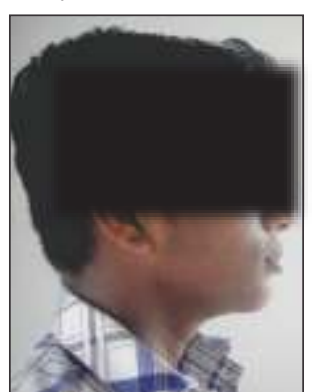

FIG 40

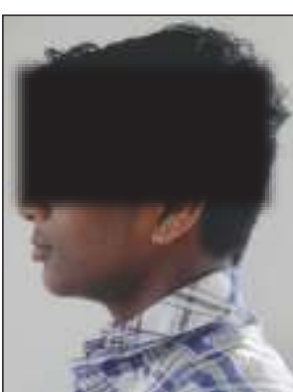

FIG 41

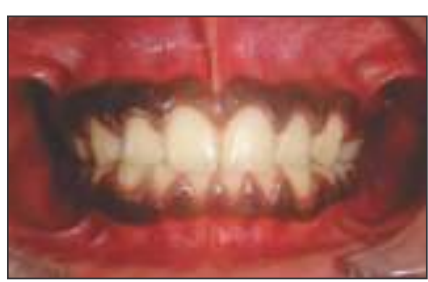

FIG 42

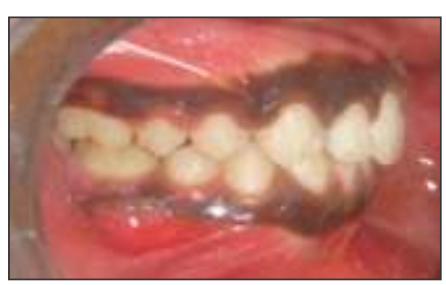

FIG 43

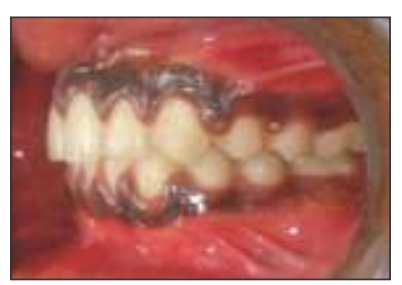

FIG 44

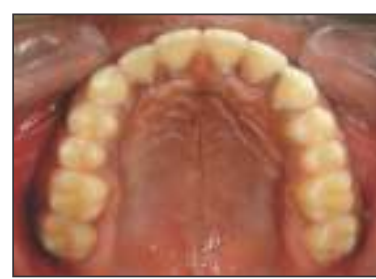

FIG 45 

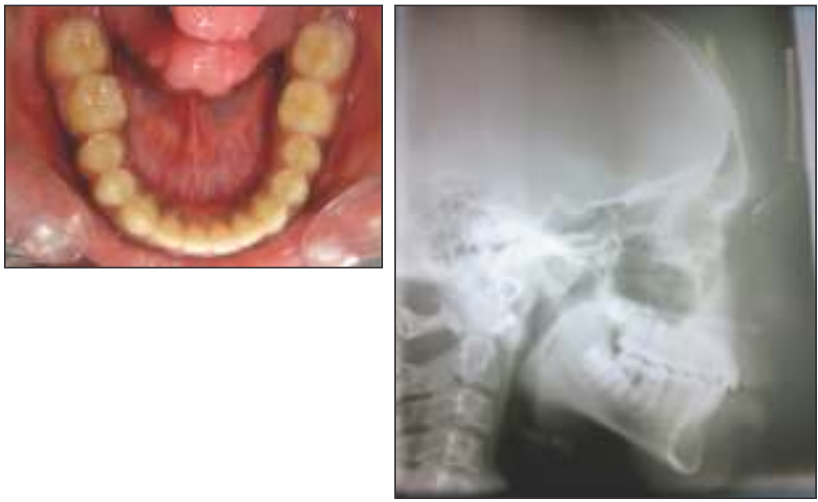

Post Treatment Cephalogram (FIG 47)

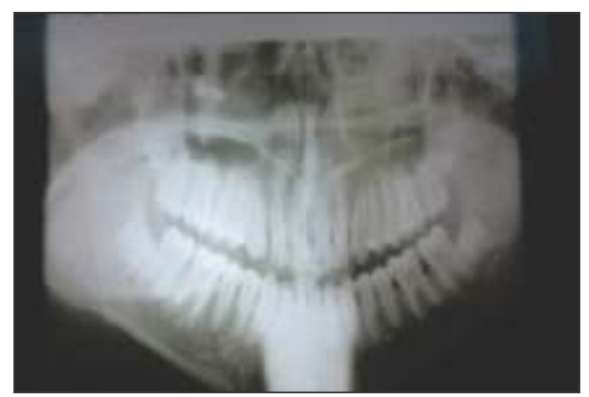

Post Treatment OPG (FIG 48)

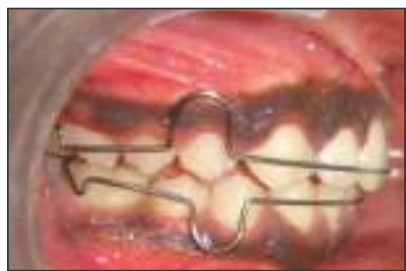

FIG 50

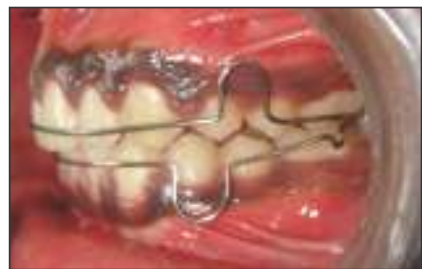

FIG 51

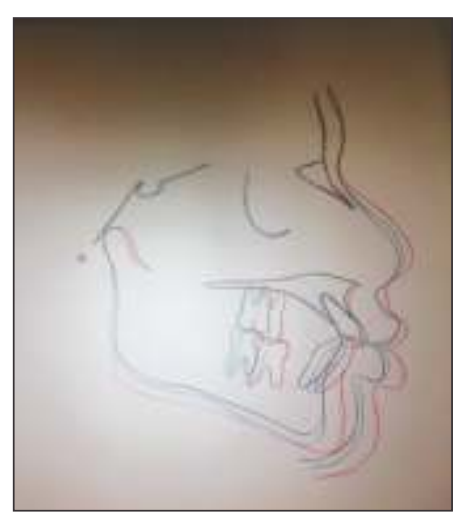

Superimposition (FIG 54)

Superimposition shows reduced nasolabial angle, increased growth of mandible, reduced proclination, achievement of a Class I relation.
Nitte University Journal of Health Science
TABLE 2

\begin{tabular}{|l|c|}
\hline Measurement & Values \\
\hline SNA & 85 \\
\hline SNB & 84 \\
\hline ANB & 1 \\
\hline WITT'S APPRAISAL & $1 \mathrm{~mm}$ \\
\hline FMA & 29 \\
\hline Sn-Go-Gn & 30 \\
\hline Upper Incisor- NA & $20 / 4$ \\
\hline Lower incisor - NB & $30 / 5$ \\
\hline Lower incisor- Mandibular plane & 98 \\
\hline Interincisal angle & 125 \\
\hline Nasolabial Angle & 95 \\
\hline
\end{tabular}

RETENTION: (FIGS 49-53)

The patient was given a modified Hawley's retainer, which was worn for a period of 12 months.

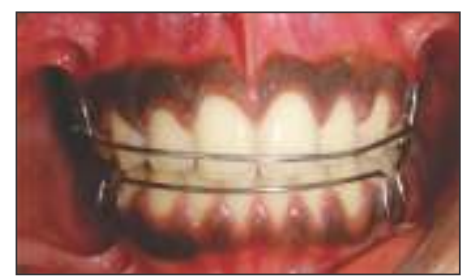

FIG 49

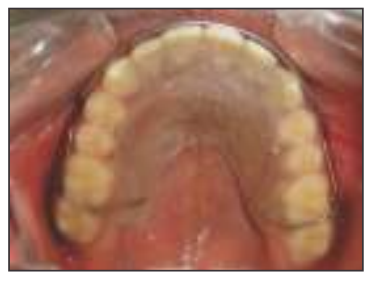

FIG 52

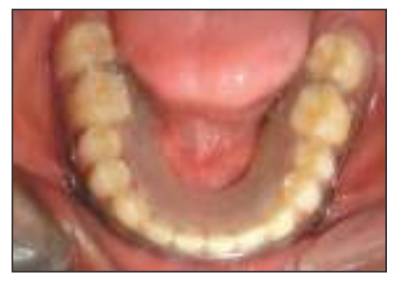

FIG 53

\section{Discussion:}

Correction of sagittal discrepancies in children can be either one phase or two phase treatment. Two phase treatment offers the advantages of earlier correction of the discrepancy, followed by a reduced period of fixed appliance treatment, reduced chances of surgery at a later date. $^{(3)}$

We chose the twin block appliance as it offers many advantages such as better patient acceptance, reduced hygiene demands, growth pattern of the patient etc.

\section{Conclusion :}

In this patient, the two phase therapy with twin block and headgear helped us achieve satisfactory results. However, long term studies with large sample sizes are needed to validate this method. 
References:

1. Clark, W. J. (1982) The Twin Block traction technique, European Journal of Orthodontics, 4, 129-138.

2. Illing, H. M., Morris, D. O. and Lee, R. T. (1998) A prospective evaluation of Bass, Bionator and Twin Block appliances. Part 1-the hard tissues, European Journal of Orthodontics, 20, 501-516

3. J.F.Camilla Tulloch, Ceib Phillips, William R. Proffit (1998) Benefit of early Class II treatment: Progress report of a two-phase randomized clinical trial, American Journal of Orthodontics and Dentofacial Orthopaedics Vol.113, Issue 1, 62-74.

4. Wieslander F.W. Long-term effect of treatment with the headgearHerbst appliance in the early mixed dentition. Stability or relapse? Am. J. Orthod. Dentofac. Orthop. 1993;104:319-329. 